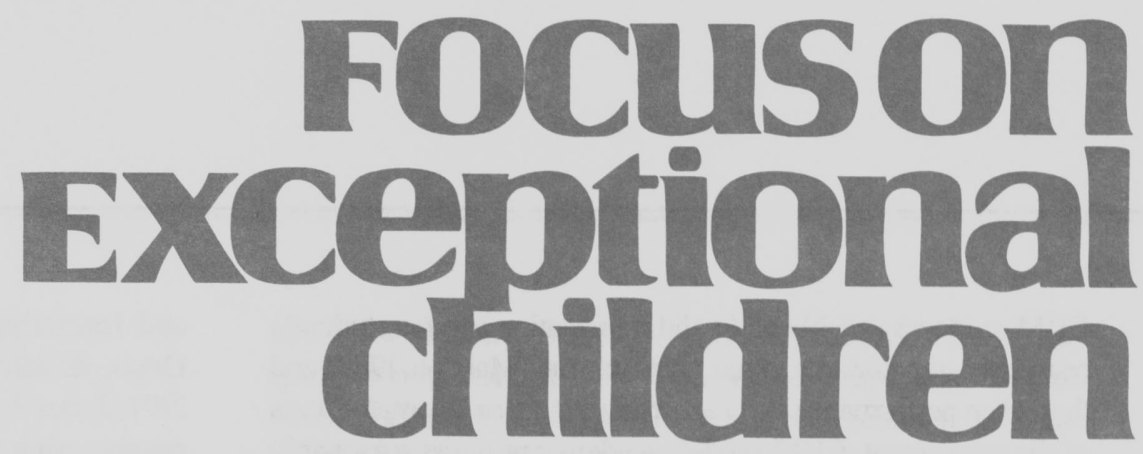

\title{
Use of Curriculum-Based Measurement in Identifying Students with Disabilities
}

\author{
Lynn S. Fuchs and Douglas Fuchs
}

The problem of overrepresentation of minority students in special education, particularly in special classes for students with mild mental retardation, has become a stimulus for scrutiny, debate, and important developments in special education. Overrepresentation has resulted in placement-bias litigation (Larry P. v. Riles, 1979/1986; Marshall et al. v. Georgia, 1984/1985; S-1 v. Turlington, 1986), which has prompted discussion and controversy over the process by which children are identified for special education (M. Polloway, 1985; Reschly, 1984, 1988; Snow, 1984) as well as the quality and value of those very services (Fuchs \& Fuchs, 1995). In turn, this discussion and controversy has led to definitional and procedural modifications in disability categories (American Association on Mental Retardation, 1992; Grossman, 1977, 1983) and corresponding epidemiological changes in the mild mental retardation and learning disability populations (Hodapp, 1995; Polloway \& Smith, 1983; Reschly, 1988).

The 1982 National Research Council's (NRC's) analysis of the problem of minority students' overrepresentation set the stage for much of the focus, tone, and substance of this activity. In the NRC report Heller, Holtzman, and Messick (1982) reformulated the problem of overrepresentation from one of discovering how to reduce disproportionality to determining the conditions under which inequality constitutes inequity of treatment. As described by Messick (1984), disproportion signifies inequity only when children are unduly exposed to classification because they receive poor quality general education, are assessed invalidly for special education, or receive an ineffective special education that hinders educational progress.

Over the past decade this reformulation of the problem has fostered calls for eligibility decision making that focuses on treatment validity-whereby the value of an assessment process is judged by its capacity to inform, foster, and document treatment effectiveness (e.g., Reschly, 1988; Reschly \& Grimes, 1995; Witt \& Gresham, 1985). One alternative assessment method frequently nominated in these calls for change is Curriculum-Based Measurement (e.g., Reschly \& Grimes, 1995; Reschly, Kicklighter, \& McKee, 1988; Sandoval, 1987; Shinn, 1995).

Curriculum-Based Measurement (CBM) (Deno, 1985) is a set of methods for indexing academic competence and progress. Based on a program of research conducted at many sites since 1977 (Deno, 1985; Shinn, 1989b), CBM specifies procedures for sampling test stimuli from local curricula, for administering and scoring those assessments, and for summarizing and interpreting the resulting database (Deno \& Fuchs, 1987). Research has documented that

The authors are Professors in the Department of Special Education at Peabody College of Vanderbilt University. 
CBM produces reliable and valid information about a student's academic standing at a given point in time (Marston, 1989) and that when performance is measured routinely on alternate forms of the assessment, CBM models academic progress reasonably well (Good, Deno, \& Fuchs, 1995).

Because the same datum, aggregated in different ways, can be used to index both standing and growth, and because a longstanding research program (Fuchs, 1993) documents CBM's capacity to inform, foster, and document treatment effectiveness, CBM can fulfill the technical requirements to achieve treatment validity. In fact, over the years, CBM has been incorporated into unified assessment systems to address a variety of psychoeducational decisions. These decisions include identifying students for special services (Marston \& Magnusson, 1988; Shinn, 1995), as well as developing intervention plans (Wesson, 1989), monitoring the effectiveness of

\section{Focuson
exceptional children}

ISSN 0015-511X FOCUS ON EXCEPTIONAL CHILDREN (USPS 203-360) is published monthly except June, July, and August as a service to teachers, special educators, curriculum specialists, administrators, and those concerned with the special education of exceptional children. This publication is annotated and indexed by the ERIC Clearinghouse on Handicapped and Gifted Children for publication in the monthly Current Index to Journals in Education (CIJE) and the quarterly index, Exceptional Children Education Resources (ECER). The full text of Focus on Exceptional Children is also available in the electronic versions of the Education Index. It is also available in microfilm from Xerox University Microfilms, Ann Arbor, MI. Subscription rates: Individual, \$30 per year; institutions, $\$ 40$ per year. Copyright (C) 1997, Love Publishing Company. All rights reserved. Reproduction in whole or part without written permission is prohibited. Printed in the United States of America. Periodicals postage is paid at Denver, Colorado. POSTMASTER: Send address changes to:

$$
\begin{gathered}
\text { Love Publishing Company } \\
\text { Executive and Editorial Office } \\
\text { P.O. Box } 22353 \\
\text { Denver, Colorado } 80222 \\
\text { Telephone (303) } 757-2579
\end{gathered}
$$

Edward L. Meyen

University of Kansas

\section{Glenn A. Vergason} Georgia State University

Richard J. Whelan

University of Kansas Medical Center

\section{Stanley F. Love Publisher}

Thomas Love Associate Editor and formatively improving those plans over time (Fuchs, Deno, \& Mirkin, 1984; Fuchs, Fuchs, Hamlett, \& Stecker, 1991; Jones \& Krouse, 1988; Wesson, 1991), decertifying and reintegrating students into general education (Allen, 1989; Fuchs, Fuchs, \& Fernstrom, 1993), and evaluating the effectiveness of school programs (Germann \& Tindal, 1985; Marston, 1987-1988).

The purpose of this article is to discuss CBM's potential contribution to an eligibility assessment process that innovatively combines a treatment validity perspective with an emphasis on the measurement of student growth. First we provide background information about how CBM was developed, how CBM integrates traditional and classroombased observational approaches to assessment, and how CBM has been used over the past 15 years to identify students for special education. Next we describe an alternative framework for incorporating CBM into an identification process that focuses on treatment validity and student growth. We present a rationale for that alternative framework, review research concerning CBM's validity within such a framework, and discuss feasibility issues this approach presents.

\section{STATEMENT OF OWNERSHIP, MANAGEMENT AND CIRCULATION}

Date of Filing: November 30, 1997

Title of Publication: Focus on Exceptional Children

Frequency of Issue: Monthly (except June, July \& August)

Location of Known Office of Publication: P.O. Box 22353, Denver, Colorado 80222-4306

Location of Headquarters of Publisher: P.O. Box 22353, Denver, Colorado $80222-4306$

Name and Address of Publisher, Editor, and Managing Editor:

Stanley F. Love, P.O. Box 22353, Denver, Colorado 80222-4306

Owner: Love Publishing Company

Extent and Nature of Circulation:

$$
\begin{array}{cc}
\text { Average No. Copies } & \text { Single Issue } \\
\text { Each Issue During } & \text { Nearest } \\
\text { Preceding } 12 \text { Months } & \text { Filing Date }
\end{array}
$$

Total No. Copies Printed

3566

3047

Paid Circulation

Sales through Dealers, etc.

Mail Subscriptions

Total Paid Circulation

Free Distribution

Total Distribution

Office Use and Left Over

Total

$\begin{array}{cc}0 & 0 \\ 2700 & 2513 \\ 2700 & 2513 \\ 759 & 462 \\ 3459 & 2975 \\ 107 & 72 \\ 3566 & 3047\end{array}$

I certify that the statements made by me above are correct and complete. 


\section{BACKGROUND INFORMATION ON CBM}

\section{Development}

In developing CBM, Deno and colleagues (see Deno, 1985) sought to establish a measurement system that (a) teachers could use efficiently; (b) would produce accurate, meaningful information with which to index growth; (c) could answer questions about the effectiveness of programs in producing academic growth; and (d) would provide information to help teachers plan better instructional programs. To accomplish this goal, a systematic program of research, conceptualized as a 3 X 3 matrix (Deno \& Fuchs, 1987), was undertaken. The rows in this matrix specified three essential questions for the development of a measurement system (what to measure, how to measure, and how to use the resulting database); the columns provided three criteria against which decisions could be formulated (technical adequacy, treatment validity, and feasibility). A 15 -year research program has addressed each of the nine cells in this matrix with multiple studies.

CBM deliberately integrates key concepts from traditional measurement theory and from the conventions of classroombased observational methodology to forge an innovative approach to assessment. As with traditional measurement, every CBM assessment samples a relatively broad range of skills: Each dimension of the annual curriculum is represented on each weekly test. Consequently, each repeated measurement is an alternate form, of equivalent difficulty, assessing the same constructs.

This principle is illustrated in CBM's spelling assessment, which samples the same relatively large domain of spelling words in the same way, to include multiple phonetic patterns and irregular spellings and to represent the same constructs and difficulty level (Fuchs, Allinder, Hamlett, \& Fuchs, 1990). This sampling strategy differs markedly from typical classroom-based assessment methods, where teachers assess mastery on a list of 10-20 words and, after mastery is demonstrated, move on to a different set of words (see Fuchs \& Deno, 1991). CBM also relies on a traditional psychometric framework by incorporating conventional notions of reliability and validity so that the standardized test administration and scoring methods yield accurate and meaningful information (Deno, Mirkin, Lowry, \& Kuehnle, 1980).

By sampling broadly and relying on standardized administration and scoring procedures, the total CBM score can be viewed as a "performance indicator": It produces a broad dispersion of scores across individuals of the same age (i.e., when measuring spelling, scores typically range from 15 to
180 letter sequences correct), with rank orderings that correspond to important external criteria, and it represents an individual's global level of competence in the domain (e.g., Deno et al., 1980). Practitioners can use this performance indicator to identify discrepancies in performance levels between individuals and peer groups, which can inform decisions about the need for special services or the point at which decertification and reintegration of students with disabilities might occur.

At the same time, however, CBM departs from conventional psychometric applications by integrating the concepts of standardized measurement and traditional reliability and validity with key features from classroom-based observational methodology: repeated performance sampling, fixed time recording, graphic displays of time-series data, and qualitative descriptions of student performance. Reliance on these classroom-based observational methods permits estimates of slope for different time periods and alternative interventions for the same individual. This creates the necessary data for testing the effectiveness of different treatments for a given student. Research also suggests that, when combined with prescriptive decision rules, these time-series analytic methods result in better instruction and learning: Teachers raise goals more often and develop higher expectations (Fuchs, Fuchs, \& Hamlett, 1989a), introduce more revisions to their instructional programs (Fuchs, Fuchs, \& Hamlett, 1989b), and effect better achievement (Fuchs, Fuchs, Hamlett, \& Stecker, 1991).

In addition, because each assessment simultaneously samples the multiple skills embedded in the annual curriculum, CBM can yield rich, qualitative descriptions of student performance to supplement the graphed, quantitative analysis of performance. These diagnostic profiles demonstrate adequate reliability and validity (see Fuchs, Fuchs, Hamlett, \& Allinder, 1989; Fuchs, Fuchs, Hamlett, Thompson, Roberts, Kubec, \& Stecker, in press), offer the advantage of being rooted in the local curriculum, provide a framework for determining strategies for improving student programs (see Fuchs, Fuchs, \& Hamlett, 1994), and result in teachers planning more varied, specific, and responsive instruction to meet individual student needs (Fuchs, Fuchs, Hamlett, \& Allinder, 1991).

Consequently, CBM bridges traditional psychometric and classroom-based observational assessment paradigms to forge an innovative approach to measurement. Through this bridging of frameworks, CBM simultaneously yields information about standing as well as change; about global competence as well as skill-by-skill mastery. Therefore, it can be used to answer questions about interindividual differences (e.g., how different is Henry's academic level from that of other students in the class, school, or district?); questions 
about intraindividual improvement (e.g., how successful is an adapted general classroom in producing better academic growth for Henry?); and questions about how to strengthen individual students' programs (e.g., on which skills in the annual curriculum does Henry require instruction?).

\section{Using CBM To Identify Students For Special Education: A Well-Established Model Focused On Performance Level}

Initially CBM was developed for two purposes: (a) to monitor academic progress and (b) to link instructional planning with assessment information to enhance student outcomes. Although CBM was not originally conceptualized or designed as a tool for identifying students for special education, studies conducted in the 1980s suggested CBM's potential utility for eligibility decisions by providing evidence that CBM differentiated school-identified students with learning disabilities (LD) from non-LD peers.

In the most ambitious study in this series, Shinn, Tindal, Spira, and Marston (1987) compared the CBM reading performance of three groups of students in grades 1-6: (a) children who had been placed in programs for students with LD based on diagnosed discrepancies between ability and achievement and who had IEP goals in the area of reading; (b) a random sample of children who received Chapter 1 remedial services; and (c) a random sample of children who received all instruction in the regular classroom with no supplemental help.

Analyses revealed statistically and clinically significant differences between the performance levels of the groups at every grade, with the exception of the comparison between LD and Chapter 1 at grade 1. In addition, when discriminant function analysis was applied to CBM reading scores, Shinn et al. found that LD students were discriminated correctly from general education students with $97 \%$ accuracy.

This pattern of findings, corroborated in related studies (e.g., Deno, Marston, Shinn, \& Tindal, 1983; Shinn \& Marston, 1985; Shinn, Ysseldyke, Deno, \& Tindal, 1986), prompted research and development on the use of CBM for formulating eligibility decisions (Marston \& Magnusson, 1988; Shinn, 1989a). In this section, we outline the methods by which CBM has been used over the past 15 years for this purpose, review evidence on the validity of this application, and discuss the assumptions, advantages, and limitations of this relatively well-established approach.

\section{Description of Procedures}

As described by Marston and Magnusson (1988) and Shinn (1989a, 1995), CBM is used to formulate eligibility de- cisions in a two-stage process: problem identification and problem certification.

Problem identification. The goal of problem identification is to determine whether an academic problem is sufficiently important to warrant further assessment (Shinn, 1989a). Toward this end, three to five CBM tests in each academic area of concern are administered on successive days on the gradeappropriate level of the school's curriculum. The median score is an estimate of the referred child's current performance level. This current performance level is compared to an expected achievement level derived from typical students in the local situation whose performance is deemed acceptable and who have been assessed using identical methods.

Procedures for sampling typical students vary in terms of completeness and elaboration. At one end of the continuum, districts mount large-scale, carefully constructed norming efforts to create complete and representative information for their local situation (Shinn, Tindal, \& Stein, 1988). At the other end, the special educator or school psychologist simply assesses three same-gender peers who have been selected randomly from a pool of students the teacher has designated as performing at an acceptable level in his or her classroom.

The method used for determining whether a problem exists corresponds to the type of norms available. When large-scale norms (at least 100 students per grade) have been developed, percentile ranks or standard deviation units are employed. If the referred student's median score falls at or below the district's 10th percentile score or between 1 and 2 standard deviations below the mean, a problem has been identified for further assessment. If, on the other hand, local norms are available only at the classroom level, discrepancies between actual and expected performances are calculated in terms of a simple ratio (expected level divided by referred student's median). If this ratio is equal to or greater than 2.0 , the problem is deemed serious enough to warrant further assessment.

Problem certification. When a problem is identified in this first stage, the student is referred for problem certification assessment, in which the purpose is to determine whether the magnitude or severity of the problem indicates that it cannot be addressed without special education (Shinn, 1995). The first step in making this determination is to use survey-level assessment to determine the student's grade placement. With surveylevel assessment, three CBM tests are administered at each successively lower level of the local curriculum. The highest curriculum level at which the student demonstrates a "successful" performance is designated the student's grade placement.

"Success" is operationalized in one of two ways, again depending on the type of norms available. If large-scale norms 
have not been collected, success is defined in terms of fixed standards (e.g., 40 to 60 words read correctly per minute in second-grade text). If, on the other hand, district norms are available, percentile ranks are used. Performance is compared to the grade-appropriate peer group for that curriculum level; that is, when a student reads fourth-grade material, the score is compared to grade 4 norms; when the student reads thirdgrade material, the score is compared to grade 3 norms. When a student's median score falls between the 25 th and 75 th percentile for typical students at that curriculum level (some districts employ the 16th to 84th percentiles), a successful performance has been achieved. The student's grade placement is the highest level of the curriculum at which the criterion is met.

In either case, the discrepancy between the level of the curriculum employed in the student's classroom (i.e., age-appropriate grade placement) and the highest level of the curriculum in which the student demonstrates a successful performance (i.e., success level) is the focus of decision making for special education placement. Each school district establishes its own criterion for how large this discrepancy must be before special education services are considered necessary to address the student's learning needs.

\section{Validity of This Approach}

Available information focuses almost exclusively on the procedures incorporated within the problem-identification phase of the CBM eligibility process. Less information is available on the survey-level assessment piece embedded within the problem certification stage. Additional investigation of the contribution and validity of this second stage is warranted, including research on the informal academic inventory procedures, the criteria for determining success levels, and cutoffs for identifying discrepancies serious enough to warrant special education (Fuchs, Fuchs, \& Deno, 1982).

With respect to the CBM problem identification procedures, however, research is promising. These methods yield students appropriate for additional assessment, as well as for special education eligibility. Deno, Marston, and Tindal (1985), for example, demonstrated that a 2.0 discrepancy ratio cutoff was useful in distinguishing Chapter 1 from LD students. In addition, as actually practiced in the Minneapolis Public Schools (Marston \& Magnusson, 1988), Student Support Teams overrode only $10 \%-15 \%$ of referrals produced via large-scale CBM screening in which students with discrepancy ratios of at least 2.0 were recommended for additional assessment. Finally, Germann and Tindal (1985) found that the CBM problem-identification procedures resulted in prevalence rates similar to state and national figures.
In addition, Marston, Mirkin, and Deno (1984) conducted a long-term screening study, in which CBM occurred weekly for 10 weeks in reading, spelling, and written expression. Three standards for determining discrepancy were applied in the three areas, creating the possibility for nine discrepancy determinations. When students evidenced three discrepancies, they were referred for special education assessment. Results indicated that $80 \%$ of CBM referrals met district guidelines for LD identification, compared to only $36 \%$ of teacher referrals. Moreover, compared to teacher referrals, CBM referrals were more evenly distributed between males and females and, at least among girls, were less influenced by social behavior.

\section{Key Features, Advantages, and Limitations}

Features. With this CBM model for formulating eligibility decisions, learning problems are viewed situationally as the discrepancy between actual and expected levels of academic competence demonstrated in the local context. This model, therefore, incorporates at least four essential features. The first two features are common to most eligibility decision-making processes: The model relies on a discrepancy model of disability or handicap, where students are judged to require special education if their performance is sufficiently different from that of a comparison group, and this discrepancy is defined completely in terms of level of performance at the time of assessment. The two additional, more novel dimensions of this model are (a) its sole focus on academic behavior, or the functional problem that prompts the referral, and (b) its situational perspective, or reliance on local standards of behavior, which means that judgments regarding the existence of a problem can vary for the same student when placed in different contexts.

Advantages. As demonstrated in practice, this CBM approach to identification offers several advantages over traditional LD identification models. First, while yielding a highly similar population of students, the CBM model is less expensive than traditional models of identification. As reported by Poland, Thurlow, Ysseldyke, and Mirkin (1982), cost estimates for the typical special education eligibility assessment process are often higher than the reimbursement for educating a child with a mild disability for an entire year. In addition, school psychologists typically devote $50 \%-75 \%$ of their time to formal testing on commercial norm-referenced instruments (Goldwasser, Meyers, Christenson, \& Graden, 1984), and school districts allocate substantial dollars to the purchase of those tests (Marston, 1989). In comparison, the CBM eligibility process is time-efficient (because test administrations are brief), and cost-efficient (because commercial materials are not required). This frees personnel and money for treatmentoriented activities. 
Efficiency, however, is not limited to time and cost. Because the assessment is linked closely to and generates information about the problems that prompted the assessment initially (i.e., the academic difficulties presented in the classroom), the assessment simultaneously informs instructional planning as it identifies students for special education. The repeated administration of several CBM tests provides teachers with information about students' instructional level. It also creates descriptions of students' strengths and weaknesses in the school's curriculum. As outlined by Reschly and Grimes (1995), linking the eligibility assessment process to instructional decision making in this way is a highly desirable goal.

In addition, as empirical evidence suggests, this model may circumvent some bias inherent in traditional approaches that rely more heavily on practitioner judgment. Marston et al. (1984) demonstrated that, compared to teacher referrals, CBM referrals more consistently met district criteria for LD eligibility; produced a more balanced distribution of boys and girls; and, at least among girls, reflected fewer behavior problems. Clearly, additional research in this area is warranted. The issue of race, for example, has not been explored.

Finally, CBM's situational notion of disability, in which problems are determined locally both in terms of the curriculum demands and in terms of the peer group, offers the logistical advantage of allowing schools to serve the students with the greatest immediate academic needs-at least as expressed in terms of discrepancies in performance level. Case studies (Shinn, 1995) illustrate how the same student's performance level may create a teaching challenge in some, but not all, situations.

For example, a student who, during problem identification, reads 25 correct words from third-grade passages would be difficult to accommodate in a classroom where the typical child read 80 correct words and the lowest student read 50 correct words. Given a classroom where the typical child reads 50 correct words and where seven classmates read 25 correct words, however, a teacher may design an instructional program addressing the needs of this child.

Limitations. Despite the clear advantages of this CBM approach over traditional LD identification procedures, it is not without controversy and limitation. For example, a traditional orientation to disability leads some (Lombard, 1988) to reject CBM's exclusive focus on academic behavior, its corresponding omission of assessment of intellectual functioning and underlying mechanisms, and its notion that the need for a special education can change across local situations.

Moreover, even when viewed from a less traditional framework, this well established CBM model for determining special education eligibility presents a fundamental limitation: It remains rooted in a static model of disability, which focuses exclusively on the level of a student's performance at one point in time. Such a one-dimensional focus on level seems unfortunate in light of two related facts.

1. Within a treatment validity perspective, measuring and enhancing growth is fundamental. For more than a decade, beginning with the NRC report in 1982, repeated calls have been issued for identification models that adopt a treatment validity orientation and that explicitly consider questions about growth: Is learning in the current instructional environment acceptable? If not, can the current instructional setting be modified to produce acceptable progress? If not, does the student, by contrast, actually demonstrate more acceptable growth with special education services?

2. Despite the established CBM model's exclusive focus on performance level, CBM actually has the unusual capacity to model academic growth and contribute to treatment effectiveness.

\section{AN ALTERNATIVE CBM APPROACH TO IDENTIFICATION FOCUSED ON GROWTH AND TREATMENT ENHANCEMENT}

\section{Capitalizing on CBM's Capacity}

This leads to a proposal for an alternative, more innovative CBM model for formulating special education eligibility decisions. This alternative CBM identification model capitalizes on CBM's capacity to focus explicitly on questions about growth and to inform and enhance teaching and learning. This multi-stage decision-making process is illustrated in Figure 1, which illustrates how the three-stage model was operationalized in one elementary school in Nashville during the 1995-1996 academic year.

\section{Phase I: Documenting Adequate Classroom Instruction and Dual Discrepancies}

Phase I begins with weekly CBM assessments for all students in the school. Every 6 weeks the school's assessment team (including the principal, school psychologist, special education teacher, and social worker) meet to review class reports and formulate two decisions. First, the team reviews each classroom to determine whether overall progress is adequate. If an overall problem seems to exist (because progress is poor relative to other classes at that grade in the school or to district norms), the psychologist meets with the teacher to adjust the classroom instructional program.

If, however, the team determines that overall progress in 


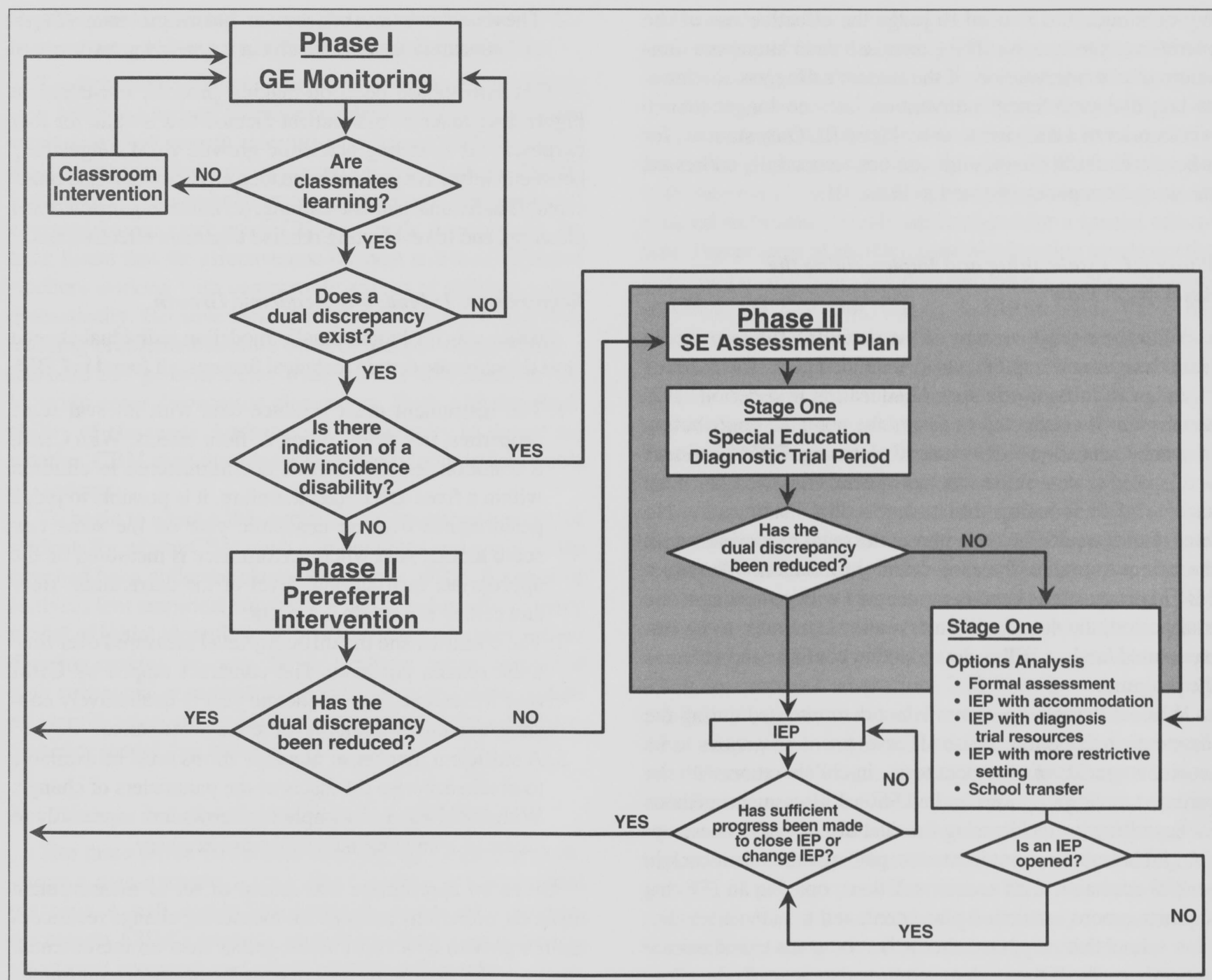

FIGURE 1

CBM Identification Model

that classroom is acceptable, the team proceeds with the second set of decisions. It reviews individual student progress to determine who meets a dual-discrepancy criterion (defined as a 1 standard deviation difference between the student's CBM median score and that of classroom peers plus a 1 standard deviation difference between the student's CBM slope of improvement and that of classroom peers).

A representative of the team consults with the classroom teacher of each student demonstrating a dual discrepancy to (a) eliminate extraneous reasons for the dual discrepancy, in which case general education CBM monitoring continues, and (b) rule out the probability of a low-incidence disabling condition (such as mental retardation, visual or hearing impairment, or autism), which would result in a decision to proceed immediately to the Options Analysis Stage of Phase III. Otherwise, students with dual discrepancies enter Phase II of decision making.

\section{Phase II: Preferral Intervention}

At least one member of the team works with the general education teacher to design an intervention that addresses the student's dual discrepancy. This intervention is implemented in general education by the general educator. CBM monitor- 
ing continues and is used to judge the effectiveness of the prereferral intervention. The general educator attempts a minimum of two interventions if the student's progress continues to lag, and prereferral intervention lasts no longer than 6 weeks prior to a decision to enter Phase III. Only students for whom prereferral intervention has not successfully addressed the dual discrepancy proceed to Phase III.

\section{Phase III: Establishing and Implementing the Assessment Plan}

With the signed consent of the parent(s), the assessment team designs and implements an extended plan. The focus of this plan is a diagnostic special education trial period. This assessment is conducted to assess the potential contribution of special education to the student's learning. CBM continues and is used to determine whether special education has been successful in reducing the student's dual discrepancy. No later than 8 weeks into this phase, the team reconvenes with the parent to review the assessment information. When successful progress has been demonstrated within the diagnostic trial period, the successful intervention continues to be implemented, and an IEP is developed to continue and enhance the program.

When differential progress is not demonstrated during the diagnostic trial period, Phase III assessment progresses to its second stage. The assessment team, in collaboration with the parent(s), reviews options and additional assessment methods for describing and addressing the dual discrepancy. These options include, but are not limited to: placing the student back in general education with accommodations; opening an IEP that requires a more restrictive placement; and transferring to another school that may have alternative resources to address the student's needs. If the student is returned to general education, CBM continues to monitor progress; if an IEP is opened, CBM also continues to determine the earliest opportunity for productively exiting the student from special education.

\section{Requirements of This Alternative CBM Model}

Within such a decision-making framework, to demonstrate the necessity for a special education, a three-pronged test must be passed.

1. The assessment must document important dual discrepancies on performance level and growth rate between the target child and peers.

2. The assessment must document that the student's rate of learning, even with general education adaptations, is inadequate.
3. The assessment must document that the provision of special education actually results in improved growth.

This three-phase decision-making process, illustrated in Figure 1, requires an assessment method that is valid for four purposes: (a) modeling academic growth, (b) distinguishing between ineffective general education environments and unacceptable individual student learning, (c) informing instructional planning, and (d) evaluating relative treatment effectiveness.

\section{Requirement 1: Modeling Academic Growth}

Instruments for longitudinally modeling individual change must demonstrate certain technical features, all found in CBM.

1. The instrument must produce data with interval scale properties, free from ceiling or floor effects. With CBM, a common test framework is administered to children within a fixed age range; therefore, it is possible to judge performance over an academic year on the same raw score metric. And when performance is measured on the appropriate instructional level of the curriculum, floor and ceiling effects do not occur.

2 . The construct and the difficulty level measured over time must remain constant: The construct tapped by CBM over the course of an academic year is qualitatively constant, and the difficulty level remains the same.

3. A sufficient number of alternate forms must be available to obtain accurate estimates of the parameters of change. With CBM one can sample the curriculum repeatedly to create as many alternate forms as necessary.

Given an appropriate instrument or set of measurement methods, current techniques for measuring change reconceptualize growth as a continuous, rather than an incremental, process. The goal is to describe trajectories, or continuous time-dependent curves, that reflect the change process. An initial step in the process is to formulate a model for change at the individual level. Fuchs, Fuchs, Hamlett, Walz, and Germann (1993), for example, examined students' academic growth rates when CBM was conducted for one school year in reading, spelling, and math; students were measured in their grade-appropriate curriculum level. For many students on each CBM measure, a linear relationship modeled student progress adequately within one academic year. These findings, in combination with corroborating evidence (Good et al., 1995; Good \& Shinn, 1990), support a tentative conceptualization of CBM growth characterized by a linear relationship, where slope is a primary parameter describing the change process. 


\section{Requirement 2: Distinguishing Between Ineffective Instruction and Unacceptable Individual Learning}

To determine whether a student's individual growth rate may indicate a serious learning problem requiring special intervention, that growth rate must be interpreted relative to those of other students receiving the same instruction. The effectiveness of general classroom instructional settings is not constant. In our work using CBM in math, for example, we have found that the effectiveness of most and least effective teachers working with comparable groups of children varies dramatically. Because lack of responsiveness and potential learning problems therefore must be judged situationally, a database that generates classwide growth rates must be collected in general education classrooms. Even with the availability of classwide databases, it is necessary to determine whether CBM dual discrepancies identify appropriate pools of students.

To begin to address this question, we examined a group of students for whom CBM math computations and applications data had been collected classwide (Fuchs, 1995). A series of analyses lent empirical support for use of a dual discrepancy model of initial identification in a first stage of a three-phase decision-making process. These findings, when combined with conceptual arguments favoring a focus on growth within an identification process, suggest the potential for a dual discrepancy model that incorporates CBM.

\section{Requirement 3: Informing Instructional Planning}

The three-phase CBM decision-making process also requires a measurement system that can inform instructional planning. A well established, longstanding research program documents CBM's capacity to help teachers plan better instructional programs and effect superior achievement. Studies have examined the specific effects of alternative data-utilization strategies, as well as CBM's overall contribution to instructional planning and student achievement.

In addition to identifying instructional level, as discussed earlier in this article, CBM has been shown to enhance teacher planning and student outcomes in three ways: (a) by helping teachers maintain appropriately ambitious student goals (Fuchs, Fuchs, \& Hamlett, 1989a), (b) by assisting teachers in determining when revisions to their instructional programs are necessary to prompt better student growth (Fuchs, Fuchs, \& Hamlett, 1989b; Stecker, 1994; Wesson, Skiba, Sevcik, King, \& Deno, 1984), and (c) providing ideas for potentially effective instructional adjustments (Fuchs, Fuchs, Hamlett, \& Allinder, 1991; Fuchs, Fuchs, \& Hamlett, 1989c; Fuchs, Fuchs, Hamlett, \& Stecker, 1991).
Research also has examined the overall efficacy and treatment validity of CBM methods within general and special education settings. This research in regular and special education corresponds, respectively, with the Phase II and Phase III goals incorporated within the alternative CBM framework for determining special education eligibility. In Phase II, the aim is to determine whether the regular education setting can be adapted sufficiently to rule out the need for a special education. This process of adapting general education to rule out the need for a special education is known widely as prereferral assessment (e.g., Graden, Casey, \& Christenson, 1985). Although current special education practice often incorporates a prereferral assessment phase (Ross, 1995), the nature of modifications often is insubstantial and the effects of those adaptations frequently are evaluated unsystematically (Fuchs \& Fuchs, 1992). With the addition of CBM, prereferral assessment can be formalized and systematized.

As described by Marston and Magnusson (1988), the Minneapolis Public Schools incorporated CBM prereferral assessment within its eligibility assessment process. Over 6 weeks, interventions were implemented and ongoing CBM data were collected to assess the extent to which the student's academic needs could be addressed in the general classroom when instructional adaptations had been introduced. Only pupils whose performance did not improve as a function of these adaptations were identified for special education services. Marston and Magnusson reported that among students initially referred, $25 \%-45 \%$ were deemed eligible for special education after the classroom intervention assessment. This figure is dramatically lower than the estimate reported by Algozzine, Christenson, and Ysseldyke (1982), in which $90 \%$ of referred students were identified subsequently for special education using conventional assessment procedures.

Phase III involves a trial diagnostic period of special education, in which CBM is used simultaneously to plan and test the effectiveness of special education for a given child. Special education eligibility is deemed appropriate and necessary only when special education demonstrates an improved growth rate. Evidence supporting CBM's utility in helping special educators plan more effective programs is strong. Studies (Fuchs, Deno, \& Mirkin, 1984; Fuchs, Fuchs, Hamlett, \& Allinder, 1991a; Fuchs, Fuchs, Hamlett, \& Ferguson, 1992; Jones \& Krouse, 1988; Stecker, 1994; Wesson, Skiba, et al., 1984; Wesson, 1991) conducted over the past decade or more provide corroborating evidence of dramatic effects on student outcomes in reading, spelling, and mathematics when special education teachers rely on CBM to inform their instructional planning. 


\section{Requirement 4: Evaluating Treatment Effectiveness}

To function adequately within the three-stage special education decision-making process proposed here, the fourth requirement is that an assessment method must provide an adequate database for evaluating treatment effectiveness-that is, for answering the following questions: Is the nonadapted general classroom environment producing adequate growth? Have adaptations introduced in the general classroom setting resulted in an improved growth rate? Has the provision of specialized services enhanced the student's learning? To answer these questions, the assessment must demonstrate sensitivity to student growth and to relative treatment effects and must permit comparisons of the effectiveness of alternative service delivery options.

Sensitivity to change and relative treatment effects. In an early study devoted to the issue of sensitivity to academic change, Marston, Fuchs, and Deno (1986) tested students on traditional, commercial achievement tests and on curriculumbased reading and written language measures early in October and 10 weeks later in December. The curriculum-based measures registered more student growth than did the traditional tests, suggesting greater sensitivity to student growth.

In an operational replication, published as a second study in the same article, Marston et al. pre- and posttested students 16 weeks apart on traditional, commercial reading achievement tests, assessed these students weekly on CBM for 16 weeks, and had teachers rate student progress in reading over this 16-week period. As with the first study, results demonstrated CBM's greater sensitivity to student growth compared to the traditional, commercial measures of reading achievement. In addition, CBM produced the largest correlation with teachers' judgments of learning; there also was a statistically significant difference between the correlation based on CBM and the one based on a traditional test.

Studies also have demonstrated that CBM slopes reflect treatment effects more sensitively than traditional measures administered on a pre/post basis. Fuchs, Fuchs, and Hamlett (1989b) showed that on the Stanford Achievement Test-Reading Comprehension Subtest, administered to detect incremental change between two points in time, change scores of the treatment groups were not significantly different. By contrast, on CBM slope data, differences between groups achieved statistical significance and were associated with a much larger effect size. This pattern, showing substantially larger effect sizes for CBM slope data, has been corroborated in other research on treatment effectiveness (Fuchs, Fuchs, Hamlett, \& Stecker, 1991; Fuchs, Fuchs, Hamlett, Phillips, \& Bentz, 1994).

Comparisons of alternative service delivery options. Evi- dence, therefore, suggests that CBM slopes may be sensitive to student growth and to the relative effects of alternative treatments. This issue is central to all three phases of the three-stage eligibility assessment process:

1. In Phase I, CBM must be sensitive to the effects of the nonadapted general classroom instructional environment.

2. In Phase II, CBM must register the potential effects of general classroom adaptations.

3. In Phase III, CBM must reveal the effects of the special intervention, if and when they occur.

Given a sensitive measurement system, however, questions remain about how that system functions when comparing student progress under alternative service delivery options. This question bears directly on Phase III of the CBM decision-making process, where the value added of a special education is estimated.

Two studies illustrate CBM's application to this type of decision making. Marston (1987-1988) compared the relative effectiveness of general and special education by analyzing slope on weekly CBM reading scores. An initial pool of 272 fourth, fifth, and sixth graders was selected for the yearlong study on the basis of performance at or below the 15th percentile on the Minneapolis Benchmark Test. The CBM reading performance of these 272 children was measured weekly. The focus of the analysis was on the 11 students who (a) spent at least 10 weeks in general education, (b) were referred to and placed in special education, and (c) spent at least 10 weeks in special education.

To determine the relative treatment effects of the two service delivery arrangements, a repeated measures analysis of variance was applied to the CBM slope data. Slopes were statistically significantly greater in special education than in general education, with the average slopes increasing from .60 to 1.15 words across the two service delivery settings. For 10 of 11 students, the slopes were larger in special education; in 7 of the 10 cases, the difference was dramatic.

In a similar way, Fuchs, Fuchs, and Fernstrom (1993) used slope to examine the relative effectiveness of special and general education for individual students as they moved in the opposite direction: as they reintegrated into general education. Twenty-one special education students had been assigned randomly to a condition designed to facilitate successful reintegration to general education classroom math instruction. Special educators used CBM to inform and strengthen planning in the area of mathematics. At the same time they monitored the target student's CBM growth and that of three low-performing members of the general education setting. When the target student's performance level ap- 
proached that of the low-performing peers, he or she was reintegrated, and the onus for instruction was transferred to the general classroom teacher. After reintegration, CBM data continued to be collected for the target student and for the low-performing peers in the general classroom. Within special education the experimental students' slopes were significantly greater than those of the low-performing peers. After reintegration, however, the slopes of the target students plunged and were significantly lower than that of the comparison students. As with the Marston study (1987-1988), this database clearly revealed the effectiveness of the special, over the general, education setting for many (although not all) students. Both studies demonstrate CBM's capacity to document the effects of service delivery options.

\section{Feasibility Questions About This Alternative CBM Model}

Research documents treatment validity: CBM can simultaneously inform, strengthen, and document the effects of interventions. Moreover, the empirical basis for CBM's technical adequacy in modeling growth and identifying pools of students appropriate for further assessment is promising. Nevertheless, questions about the feasibility of such a system remain. These questions address schools' capacity to conduct routine CBM data collection on large numbers of students and their capacity to integrate the three phases into a smoothly operating eligibility decision-making process.

\section{Routine CBM Data Collection}

When administered individually by teachers, CBM can be time-consuming. Observations of teachers conducting CBM indicate that to prepare, provide directions for, administer, and score one assessment, and to graph and analyze data for one student in one academic area, a teacher devotes approximately 2.5 minutes (Fuchs, Fuchs, Hamlett, \& Hasselbring, 1987; Wesson, Fuchs, Tindal, Mirkin, \& Deno, 1986). Multiplied over a class of 25 pupils and over two academic areas, weekly assessment requires substantial allocation of teacher time.

Despite these figures, some school districts have demonstrated the capacity to conduct weekly, schoolwide CBM data collection. Hiawatha Elementary School in Minneapolis, for example, employs support staff, aides, and volunteers to collect CBM reading data on every student in the school, every week of the year (Self, Benning, Marston, \& Magnusson, 1991). Clearly, however, such an effort requires systemic support at the school level.

In an effort to address the time required to collect and manage an ongoing assessment database, we have developed computer applications over the past decade (see Fuchs, Fuchs, \& Hamlett, 1993; Fuchs, Fuchs, \& Hamlett, 1994, for summaries of the related research programs). This software automatically (a) administers and scores the assessments as students work at computers; (b) provides performance feedback to students; (c) graphs performance over time and calculates slopes of growth; (d) applies decision rules to the graphed data and makes recommendations to raise goals or change programs accordingly; (e) summarizes students' strengths and weaknesses in the curriculum; (f) analyzes the assessment profile and interacts with the teacher to formulate recommendations about how to adjust the teaching program for individual students; and $(\mathrm{g})$ produces classwide reports that summarize the performance of the class, make large- and small-group teaching recommendations, and automatically identify students with dual discrepancies.

This software eliminates the time that teachers devote to the mechanics of implementing CBM and increase satisfaction with the process (Fuchs, Hamlett, Fuchs, Stecker, \& Ferguson, 1988). Moreover, computers can greatly facilitate the analytic methods required for the three-phase decision-making process, such as calculating class means and standard deviations on CBM slope and level, identifying students who meet the dual-discrepancy criterion for further assessment, determining whether general classroom adaptations have produced improved growth rates, and identifying whether special education enhances learning. Over the past 5 years, numerous school systems have relied on these computer programs to facilitate CBM data collection.

\section{Integrating the Three Assessment Phases}

Despite evidence that CBM can be collected routinely on large numbers of students, along with research demonstrating CBM's potential capacity to satisfy the technical requirements associated with the three-stages of the decision-making process, it remains unknown whether the phases can be integrated smoothly into an eligibility process, and, if so, what the costs, outcomes, and unintended consequences might be.

In 1994 the Minneapolis Public Schools initiated an experimental program to pilot an eligibility assessment process that resembles the CBM eligibility assessment process discussed in this article. In the experimental Minneapolis model (Minneapolis Public Schools, 1993), students can be considered as having a handicap and qualify for special education services if they meet three criteria:

1. In one or more basic skills areas, achievement falls at least 1.75 deviations below the mean on a standardized measure. 
2. The student's rate of progress is below the rate expected for the area and grade level despite implementation of two or more well-designed instructional interventions over a 4-6 week period.

3. Necessary interventions will require assistance for a sustained period or are beyond the expectations for instruction provided by general education personnel.

Minneapolis procedures incorporate many of the same constructs described and methods incorporated within the model proposed in this article. One major distinction is the omission from the Minneapolis model of a third phase, wherein a diagnostic special education assessment period is conducted prior to an eligibility decision. On the other hand, the first two phases are similar and, according to D. Marston (personal communication, April 3, 1995), the long-term expectation is that CBM will be incorporated throughout the decision-making process. In fact, among the 20 waiver schools, approximately eight rely on schoolwide CBM data collection to provide much of the required database.

Currently Minneapolis (Minneapolis Public Schools, 1993) is engaged in a comprehensive evaluation of this experimental model to identify its effects on the general quality of the academic program, the extent of integration of students with disabilities, qualifications of the teaching staff who provide special services, quality of IEPs and multidisciplinary team processes, as well as costs and assurances (in terms of parental choice, eligibility, and due process).

\section{CONCLUDING COMMENTS}

The purpose of the three-phase special education eligibility assessment process proposed in this paper is twofold.

1. It seeks to identify and correct learning problems in the general classroom environment whenever possible.

2. Its objective is to increase the probability that children who are designated for a special education actually require and benefit from those additional services.

In achieving these two goals, this treatment-oriented assessment process may or may not reduce the problem of overrepresentation of minority students in special education; that question remains to be addressed empirically. Whether it does or does not reduce disproportion, however, this assessment process should eliminate the inequity potentially associated with overrepresentation of minority students in special education. This is achieved in part because the assessment process focuses systematic and intensive effort at maximizing the potential of general education for the individual student and reserves judgment about the need for special education until the effects of individual adaptations within the general classroom environment have been explored. More important, however, equity is achieved when, prior to placement, evidence verifies that a special education program is actually valuable and desirable because it enhances the learning of the specific individual. This third phase of the assessment process is, consequently, crucial to the achievement of equity.

Nevertheless, in addition to achieving equity through these goals, one can anticipate that this three-phase decisionmaking process-just as any innovative assessment process-will result in unintended consequences. For example, one might anticipate that this process will decrease the number of students identified as having a disability. This may occur because the process requires demonstration of dual, rather than single, discrepancies and because, unlike other identification processes, it requires systematic evidence not only of general education's inability but also of special education's capacity to address students' learning problems.

Depending on bureaucratic response to reductions in identification rates, the corresponding effects could represent new potential or additional challenge for special education. If funding remains constant, a reduction in the special education prevalence rate may enhance the overall efficacy of special education by providing special educators better opportunities to provide individualized, intensive instruction (Fuchs \& Fuchs, 1995). If on the other hand, a reduction of special education roles results in funding cuts, it may interfere with students' opportunities to receive much required assistance.

Because one can anticipate this, as well as other unintended consequences, one must reserve judgment about the utility and validity of the three-phase decision-making process. Although its components have been studied separately, the three-stage decision-making process remains to be researched at the systemic level so the costs, benefits, and unintended consequences of such a process can be tested and understood thoroughly.

\section{REFERENCES}

Algozzine, B., Christenson, S., \& Ysseldyke, J. E. (1982). Probabilities associated with the referral to placement process. Teacher Education \& Special Education, 5(3), 19-23.

Allen, D. (1989). Periodic and annual reviews and decision to terminate special education services. In M. R.. Shinn (Ed.), Curriculum-based measurement: Assessing special children (pp. 182-201). New York: Guilford.

American Association on Mental Retardation (1992). Mental retardation: Definition, classification, and systems of supports (9th 
ed.). Washington, DC: Author.

Deno, S. L. (1985). Curriculum-based measurement: The emerging alternative. Exceptional Children, 52, 219-232.

Deno, S. L., \& Fuchs, L. S. (1987). Developing curriculum-based measurement systems for data-based special education problem solving. Focus on Exceptional Children, 19(8), 1-16.

Deno, S. L., Marston, D., Shinn, M., \& Tindal, G. (1983). Oral reading fluency: A simple datum for scaling reading disability. Topics in Learning \& Learning Disability, 2(4), 53-59.

Deno, S. L., Marston, D., \& Tindal, G. (1985). Direct and frequent curriculum-based measurement: An alternative for educational decision making. Special Services in the Schools, 2, 5-28.

Deno, S. L., Mirkin, P., Lowry, L., \& Kuehnle, K. (1980). Relationships among simple measures of spelling and performance on standardized achievement tests (Research Report No. 22). Minneapolis: University of Minnesota Institute for Research on Learning Disabilities.

Fuchs, D., \& Fuchs, L. S. (1992). Limitations of a "feel-good" approach to consultation. Journal of Educational and Psychological Consultation, 3, 93-97.

Fuchs, D., \& Fuchs, L. S. (1995). What's special about special education? Phi Delta Kappan, 76, 522-530.

Fuchs, D., Fuchs, L. S., \& Fernstrom, P. J. (1993). A conservative approach to special education reform: Mainstreaming through transenvironmental programming and curriculum-based measurement. American Educational Research Journal, 30, 149-178.

Fuchs, L. S. (1993). Enhancing instructional programming and student achievement with curriculum-based measurement. In J. J. Kramer (Ed.), Curriculum-based assessment (pp. 65-104). Lincoln, NE: Buros Institute of Mental Measurements, University of Nebraska.

Fuchs, L. S. (1995, May). Curriculum-based measurement and eligibility decision making: An emphasis on treatment validity and growth. Paper presented for the Workshop on IQ Testing and Educational Decision Making, National Research Council, National Academy of Sciences, Washington, DC.

Fuchs, L. S., Allinder, R. M., Hamlett, C. L., \& Fuchs, D. (1990). An analysis of spelling curricula and teachers' skills in identifying error types. Remedial \& Special Education, 11(1), 42-53.

Fuchs, L. S., \& Deno, S. L. (1991). Paradigmatic distinctions between instructionally relevant measurement models. Exceptional Children, 57, 488-501.

Fuchs, L. S., Deno, S. L., \& Mirkin, P. K. (1984). The effects of frequent curriculum-based measurement and evaluation on student achievement, pedagogy, and student awareness of learning. American Educational Research Journal, 21, 449-460.

Fuchs, L. S., Fuchs, D., \& Deno, S. L. (1982). Reliability and validity of curriculum-based informal reading inventories. Reading $R e$ search Quarterly, 18, 6-26.

Fuchs, L. S., Fuchs, D., \& Hamlett, C. L. (1989a). Effects of alternative goal structures within curriculum-based measurement. Exceptional Children, 55, 429-438.
Fuchs, L. S., Fuchs, D., \& Hamlett, C. L. (1989b). Effects of instrumental use of curriculum-based measurement to enhance instructional programs. Remedial \& Special Education, 10(2), 43-52.

Fuchs, L. S., Fuchs, D., \& Hamlett, C. L. (1989c). Monitoring reading growth using student recalls: Effects of two teacher feedback systems. Journal of Educational Research, 83, 103-111.

Fuchs, L. S., Fuchs, D., \& Hamlett, C. L. (1993). Technological advances linking the assessment of students' academic proficiency to instructional planning. Journal of Special Education Technology, 12, 49-62.

Fuchs, L. S., Fuchs, D., \& Hamlett, C. L. (1994). Strengthening the connection between assessment and instructional planning with expert systems. Exceptional Children, 61, 138-146.

Fuchs, L. S., Fuchs, D., Hamlett, C. L., \& Allinder, R. M. (1989). The reliability and validity of skills analysis within curriculumbased measurement. Diagnostique, 14, 203-221.

Fuchs, L. S., Fuchs, D., Hamlett, C. L., \& Allinder, R. M. (1991). Effects of expert system advice within curriculum-based measurement on teacher planning and student achievement in spelling. School Psychology Review, 20, 49-66.

Fuchs, L. S., Fuchs, D., Hamlett, C. L., \& Ferguson, C. (1992). Effects of expert system consultation within curriculum-based measurement using a reading maze task. Exceptional Children, $58,436-450$.

Fuchs, L. S., Fuchs, D., Hamlett, C., \& Hasselbring, T. S. (1987). Using computers with curriculum-based progress monitoring. Journal of Special Education Technology, 8(4), 14-27.

Fuchs, L. S., Fuchs, D., Hamlett, C. L., Phillips, N. B., \& Bentz, J. (1994). Classwide curriculum-based measurement: Helping general educators meet the challenge of student diversity. Exceptional Children, 60, 518-537.

Fuchs, L. S., Fuchs, D., Hamlett, C. L., \& Stecker, P. M. (1991). Effects of curriculum-based measurement and consultation on teacher planning and student achievement in mathematics operations. American Educational Research Journal, 28, 617-641.

Fuchs, L. S., Fuchs, D., Hamlett, C. L., Thompson, A., Roberts, P. H., Kubec, P., \& Stecker, P. M. (in press). Technical features of a mathematics concepts and applications curriculum-based measurement system. Diagnostique.

Fuchs, L. S., Fuchs, D., Hamlett, C. L., Walz, L., \& Germann, G. (1993). Formative evaluation of academic progress: How much growth can we expect? School Psychology Review, 22, 27-48.

Fuchs, L. S., Hamlett, C. L., Fuchs, D., Stecker, P. M., \& Ferguson, C. (1988). Conducting curriculum-based measurement with computerized data collection: Effects on efficiency and teacher satisfaction. Journal of Special Education Technology, 9(2), 73-86.

Germann, G., \& Tindal, G. (1985). An application of curriculumbased assessment: The use of direct and repeated measurement. Exceptional Children, 52, 244-265.

Goldwasser, E., Meyers, J., Christenson, S., \& Graden, J. (1984). The impact of PL 94-142 on the practice of school psychology: A 
national survey. Psychology in the Schools, 20, 152-165.

Good, R. H., Deno, S. L., \& Fuchs, L. S. (1995, February). Modeling academic growth for students with and without disabilities. $\mathrm{Pa}-$ per presented at third annual Pacific Coast Research Conference, Laguna Beach, CA.

Good, R. H., \& Shinn, M. R. (1990). Forecasting accuracy of slope estimates for reading curriculum-based measurement: Empirical evidence. Behavioral Assessment, 12, 179-194.

Graden, J. L., Casey, A., \& Christenson, S. L. (1985). Implementing a preferral intervention system: Part I. The model. Exceptional Children, 51, 377-384.

Grossman, H. J. (Ed.). (1977). Manual on terminology and classification in mental retardation (rev. ed.). Baltimore: American Association on Mental Deficiency/Garamond/Pridemark.

Grossman, H. J. (Ed.). (1983). Classification in mental retardation (3d ed.). Washington, DC: American Association on Mental Deficiency.

Heller, K. A., Holtzman, W. H., \& Messick, S. (Eds.). (1982). Placing children in special education: A strategy for equity. Washington, DC: National Academy Press.

Hodapp, R. M. (1995). Definitions in mental retardation: Effects on research, practice, and perceptions. School Psychology Quarterly, 10, 24-28.

Jones, E. D., \& Krouse, J. P. (1988). The effectiveness of data-based instruction by student teachers in classrooms for pupils with mild learning handicaps. Teacher Education \& Special Education, 11, 9-19.

Larry P. v. Riles. 343 F. Supp. 1306 (N.D. Cal. 1972) (preliminary injunction). Aff'd 502 F. 2d 963 (9th cir. 1974); 495 F. Supp. 926 (N.D. Cal. 1979) (decision on merits). Order modifying judgment, C-71-2270 RFP, Sept. 25, 1986.

Lombard, T. (1988). Curriculum-based measurement: Megatesting or McTesting. School Psychology in Minnesota, 20(2), 27-32.

Marshall et al. v. Georgia. U. S. District Court for Southern District of Georgia, CV482-233, June 28, 1984; Aff'd (11th cir. no 848771 , Oct. 29, 1985).

Marston, D. (1987-1988). The effectiveness of special education: A time-series analysis of reading performance in regular and special education settings. Journal of Special Education, 21(4), 13-26.

Marston, D. (1989). Curriculum-based measurement: What is it and why do it? In M. R. Shinn (Eds.), Curriculum-based measurement: Assessing special children (pp. 18-78). New York: Guilford.

Marston, D., Fuchs, L. S., \& Deno, S. L. (1986). Measuring pupil progress: A comparison of standardized achievement tests and curriculum-related measures. Diagnostique, 11, 71-90.

Marston, D., \& Magnusson, D. (1988). Curriculum-based assessment: District-level implementation. In J. Graden, J. Zins, \& M. Curtis (Eds.), Alternative educational delivery systems: Enhancing instructional options for all students (pp. 137-172). Washington, DC: National Association of School Psychologists.
Marston, D., Mirkin, P., \& Deno, S. (1984). Curriculum-based measurement: An alternative to traditional screening, referral, and identification. Journal of Special Education, 18, 109-117.

Messick, S. (1984). Assessment in context: Appraising student performance in relation to instructional quality. Educational Researcher, 13(3), 3-8.

Minneapolis Public Schools (1993). Special education experimental program proposal. Minneapolis: Author.

Poland, S., Thurlow, M. L., Ysseldyke, J. E., \& Mirkin, P. K. (1982). Current psychoeducational assessment and decision-making practices as reported by directors of special education. Journal of School Psychology, 20, 171-179.

Polloway, E. A., \& Smith, J. D. (1983). Changes in mild mental retardation: Population, programs, and perspectives. Exceptional Children, 50, 149-159.

Polloway, M. (1985). Identification and placement in mild mental retardation programs: Recommendations for professional practice. Education \& Training of the Mentally Retarded, 20, 218-221.

Reschly, D. J. (1984). Beyond IQ test bias: The National Academy Panel's analysis of minority EMR overrepresentation. Educational Researcher, 13(3), 15-19.

Reschly, D. J. (1988). Minority MMR overrepresentation and special education reform. Exceptional Children, 54, 316-323.

Reschly, D. J., \& Grimes, J. P. (1995). Best practices in intellectual assessment. In A. Thomas \& J. Grimes (Eds.), Best practices in school psychology (Vol. 3, pp. 763-773). Washington, DC: National Association of School Psychologists.

Reschly, D. J., Kicklighter, R., \& McKee, P. (1988). Recent placement litigation Part III: Analysis of differences in Larry P., Marshall and $S-1$ and implications for future practice. School Psychology Review, 17, 39-50.

Ross, R. P. (1995). Best practices in implementing intervention assistance teams. In A. Thomas \& J. Grimes (Eds.), Best practices in school psychology (Vol. 3, pp. 227-237). Washington, DC: National Association of School Psychologists.

S-1 v. Turlington. Preliminary injunction, U.S. Dist. Court, Southern Dist. of Florida, Case No. 79-8120-Civ-CA WPB, June 15, 1979. Aff' $d$ United States Court of Appeals, 5th Circuit, Jan. 26, 1981, 635 F 2d 342 (1981). Trial on Merits, May 19-June 4, 1986.

Sandoval, J. (1987). Larry who? Coping with the extended ban on IQ tests for black children. Trainer's Forum: The Newsletter of Trainers of School Psychology, 7, 2-3.

Self, H., Benning, A., Marston, D., \& Magnusson, D. (1991). Cooperative teacher project: A model for students at risk. Exceptional Children, 58, 26-35.

Shinn, M. R. (1989a). Case study of Ann H: From referral to annual review. In M. R. Shinn (Ed.), Curriculum-based measurement: Assessing special children (pp. 90-129). New York: Guilford.

Shinn, M. R. (Ed.). (1989b). Curriculum-based measurement: Assessing special children. New York: Guilford.

Shinn, M. R. (1995). Best practices in curriculum-based measurement and its use in a problem-solving model. In A. Thomas \& J. 


\title{
NEW 1998 EDITION
}

\section{Free Appropriate Public Education: The Law and Children with Disabilities-Fifth Edition}

\author{
H. Rutherford Turnbull, University of Kansas \\ Ann Turnbull, University of Kansas
}

This definitive resource covers legislation, case law techniques, due process, parent participation, and much more. The text is completely updated and contains all the substantial amendments made by the 1997 reauthorization of IDEA. The book also reports the pre-1997 provisions of IDEA so that comparisons to the current law can be made. The cases presented in this edition represent those that are widely regarded as "leading" or those that are quite recent and represent an established body of law. By being selective, this text focuses on the most important special education law cases and gives detailed analysis of the court's decisions.

\section{Special Features}

- Completely updated with amendments made by 1997 reauthorization of IDEA

- Detailed analysis of most important cases affecting special education law

- Presents significant pre-1997 provisions of IDEA

- Glossary to explain legal terminology

\section{Contents}

1. Introduction to the American Legal System

2. Federal Policy and Disability

3. Zero Reject

4. Testing, Classification, and Placement

5. Appropriate Education
6. Least Restrictive Appropriate Educational Placement

7. Procedural Due Process

8. Parent Participation and Shared Decision Making

9. Compliance Through the Courts

10. Enforcement of Six Principles and Systems-Change for School Reform

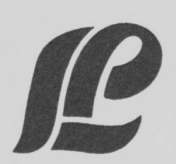

LOVE PUBLISHING COMPANY

P.O. Box 22353

Denver, CO 80222

303-757-2579 • Fax 303-782-5683 
Grimes (Eds.), Best practices in school psychology (Vol. 3, pp. 547-567). Washington, DC: National Association of School Psychologists.

Shinn, M. R., \& Marston, D. (1985). Differentiating mildly handicapped, low-achieving, and regular education students: A curriculum-based approach. Remedial \& Special Education, 6, 31-45.

Shinn, M. R., Tindal, G., Spira, D., \& Marston, D. (1987). Practice of learning disabilities as social policy. Learning Disability Quarterly, 10, 17-28.

Shinn, M. R., Tindal, G., \& Stein, S. (1988). Curriculum-based assessment and the identification of mildly handicapped students: A research review. Professional School Psychology, 3, 69-85.

Shinn, M. R., Ysseldyke, J. E., Deno, S. L., \& Tindal, G. (1986). A comparison of differences between students labeled learning disabled and low achieving on measures of classroom performance. Journal of Learning Disabilities, 19, 545-552.

Snow, R. E. (1984). Placing children in special education: Some comments. Educational Researcher, 13(3), 12-14.

Stecker, P. M. (1994). Effects of instructional modifications with and without curriculum-based measurement on the mathematics achievement of students with mild disabilities. Unpublished doctoral dissertation, Vanderbilt University, Nashville, TN.
Wesson, C. L. (1989). An efficient technique for establishing reading groups. The Reading Teacher, 466-469.

Wesson, C. L. (1991). Curriculum-based measurement and two models of follow-up consultation. Exceptional Children, 57, 246-257.

Wesson, C. L., Fuchs, L. S., Tindal, G., Mirkin, P. K., \& Deno, S. L. (1986). Facilitating the efficiency of ongoing curriculum-based measurement. Teacher Education \& Special Education, 9, 166-172.

Wesson, C. L., Skiba, R., Sevcik, B., King, R., \& Deno, S. (1984). The effects of technically adequate instructional data on achievement. Remedial \& Special Education, 5, 17-22.

Witt, J. C., \& Gresham, F. M. (1985). Review of the Wechsler Intelligence Scale for Children-Revised. In J. Mitchell (Ed.), Ninth mental measurements yearbook (pp. 1716-1719). Lincoln, NE: Buros.

This manuscript is based in part on a paper prepared for the Workshop on IQ Testing and Educational Decision Making, National Research Council, National Academy of Sciences, May 11, 1995.

\section{PERMISSIONS AND COPYRIGHT}

All rights are reserved. No part of this publication may be reproduced, photocopied, faxed, stored in a retrieval system, or transmitted, in any form or by any means, electronic, mechanical, recording or otherwise, without the prior written permission of the publisher.
Back issues are available for sale. Reproduction requires permission and payment of fees. It is illegal and a violation of federal copyright law to reproduce this publication without permission. Direct all inquiries to the permissions editor. 